\title{
Gestión de proyectos de diseño sustentable en planteles educativos de educación superior
}

\section{Sustainable Design Project Management in Schools of Higher Education}

Gestão de projetos de design sustentável em escolas de ensino superior

Omar Eduardo Sánchez Estrada

Universidad Autónoma del Estado de México, México

omarseuaem@yahoo.com.mx

https://orcid.org/0000-0002-0108-0642

\section{Resumen}

Debido a la importancia actual de los problemas sociales, de deterioro ambiental y económicos en los centros de estudios superiores, el presente trabajo tiene como objetivo analizar e identificar las competencias generales y específicas requeridas para gestionar proyectos de diseño sustentable. Esto a partir de los diferentes factores que favorecen la toma de decisiones, así como de elementos teóricos de apoyo para su implementación en los planteles educativos de nivel superior. La metodología se centró en técnicas observacionales. A través de un estudio de transversalidad entre las distintas competencias de sustentabilidad, diseño, administración y de liderazgo, se partió de la valoración de cada uno de los elementos que integran esta actividad. Aunado a lo anterior, se aplicó un cuestionario, con base en los conceptos y criterios resultantes, a gestores investigadores de la Universidad Autónoma del Estado de México, Centro Universitario Valle de Chalco. Para dar fiabilidad a los datos obtenidos, se trabajó con la teoría de la información, y en especial con el procedimiento denominado distancia de Hamming. Las capacidades y 


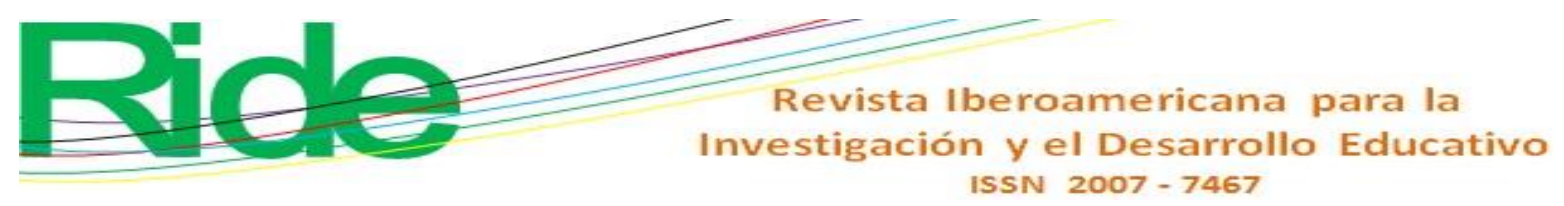

habilidades relevantes aquí obtenidas no solo impactarán favorablemente en el planteamiento, desarrollo y cumplimiento de objetivos, sino también en el desarrollo de los planes curriculares en las distintas áreas de aplicación y el ejercicio docente.

Palabras clave: competencias, estrategias de gestión, proyectos, sustentabilidad.

\section{Abstract}

Due to the importance of social problems, environmental and economic deterioration in higher education centers, the present work aims to analyze and identify the general and specific competences required to manage sustainable design projects. This based on the different factors that favor decision-making, as well as theoretical elements of support for its implementation in higher education schools. The methodology was focused on observational techniques, through a study of transversality between the different competencies of sustainability, design, administration and leadership, based on the assessment of each of the elements that make up this activity. In addition, a questionnaire was applied based on the concepts and resulting criteria to research managers of the Universidad Autónoma del Estado de México, Centro Universitario Valle de Chalco. In order to give reliability to the obtained data, we worked with the Hamming distance process. As a result of the theoretical analysis and the application of the validation technique, the relevant skills and abilities were presented, which will not only impact favorably on the planning, development and fulfillment of objectives, but also on the development of the curricular plans in the different areas of application and teaching practice.

Keywords: competencies, management strategies, projects, sustainability. 


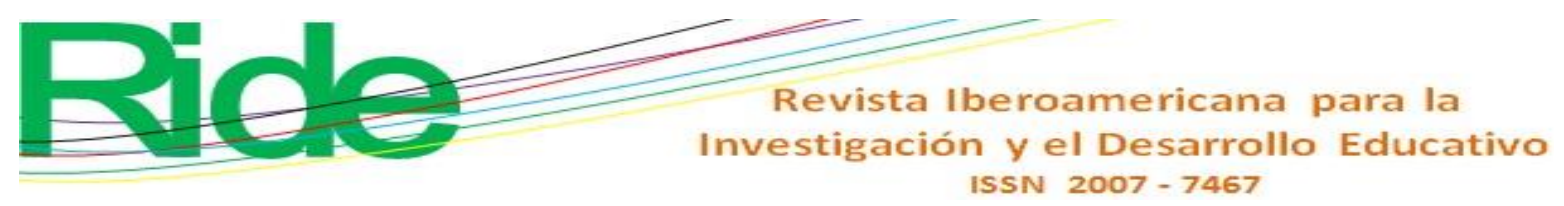

\section{Resumo}

Devido à atual importância dos problemas de deterioração social, ambiental e econômica nos centros de ensino superior, o presente trabalho tem como objetivo analisar e identificar as competências gerais e específicas necessárias para gerenciar projetos de design sustentáveis. Isto é baseado nos diferentes fatores que favorecem a tomada de decisão, bem como elementos de apoio teórico para sua implementação em estabelecimentos de ensino superior. A metodologia focada em técnicas observacionais. Através de um estudo transversal entre as diferentes competências de sustentabilidade, design, administração e liderança, baseou-se na avaliação de cada um dos elementos que compõem essa atividade. Além do exposto, aplicou-se um questionário, baseado nos conceitos e critérios resultantes, para pesquisadores da Universidade Autônoma do Estado do México, Centro Universitário Valle de Chalco. Para dar confiabilidade aos dados obtidos, trabalhamos com teoria da informação e, principalmente, com o procedimento denominado distância de Hamming. As habilidades e habilidades relevantes obtidas aqui terão impacto positivo na abordagem, desenvolvimento e cumprimento de objetivos, mas também no desenvolvimento de planos curriculares nas diferentes áreas de aplicação e ensino.

Palavras-chave: competências, estratégias de gestão, projetos, sustentabilidade.

Fecha Recepción: Septiembre 2018

Fecha Aceptación: Agosto 2019

\section{Introducción}

Las investigaciones actuales deben centrarse en atender situaciones que están rebasando los límites del planeta (Duarte, 2006). Cada país tiene diferentes políticas y acciones en materia de medio ambiente, dependiendo de sus recursos naturales, actividades productivas, culturales o de recreación. En los últimos años ha aumentado el interés por cuidar el mundo y las acciones de los seres vivos. El Informe Brundtland (Organización de las Naciones Unidas [ONU], también llamado Nuestro Futuro Común, publicado en 1987, declara, entre otras cosas, que para lograr un desarrollo sustentable es necesario un sistema de producción que respete la obligación de preservar la base ecológica para el desarrollo y un procedimiento tecnológico que sea capaz de encontrar continuamente nuevas soluciones, 
partiendo de la satisfacción de las necesidades del presente sin comprometer las necesidades de las futuras generaciones. De acuerdo con Økland (2015), la sustentabilidad en la gestión de proyectos tiene cada vez mayor importancia, ya que los problemas de contaminación y procesos productivos, por mencionar un par, están afectando considerablemente el medio ambiente.

Actualmente es posible encontrar información detallada de los proyectos desarrollados. Al respecto, un tercio del producto mundial bruto (suma del producto nacional bruto [PNB] de todos los países del mundo) se realiza a través de estos desarrollos (Turner, Huemann, Anbari y Bredillet, 2010). Sin embargo, existe una brecha entre las metodologías, herramientas y marcos presentados en la literatura académica y la práctica común, tal y como lo muestran los estándares de la gestión (Ali, Boks y Bey, 2016).

La Organización para la Cooperación y el Desarrollo Económico [OCDE] (2012) afirma que se debe trabajar en conjunto ante problemas globales como el cambio climático o la destrucción de la capa de ozono, que afectan a cualquier región del mundo. La perspectiva medioambiental hacia el 2050, según la misma OCDE (2012), es que la población mundial pasará de 7000 millones de personas a más de 9000 millones, y pronostica que la economía mundial crecerá casi cuatro veces y, por ende, aumentará la demanda energética y la de los recursos naturales. Se estima, asimismo, que un crecimiento económico global 400 \% mayor requerirá 80 \% más energía. En sintonía con lo anterior, la degradación y erosión del capital ambiental natural presentarán un riesgo irreversible que podría poner en peligro dos siglos de crecimiento en los estándares de vida.

La Agenda 21 universitaria, también enfocada en la gestión ambiental, afirma que la educación superior debe formar nuevas generaciones en el modelo de sustentabilidad integral, en el cual se presenta una perfecta correspondencia entre los diferentes procesos académicos, administrativos y operativos, además de contribuir en la generación y aplicación del conocimiento, así como en la conducta de una sociedad actual (Marcote y Suárez, 2011).

Por otro lado, se sabe que existe una crisis en el ámbito económico, cuyas repercusiones son más evidentes en las estructuras y características del trabajo asalariado, y que los organismos internacionales, gobiernos e instituciones de alguna manera persiguen

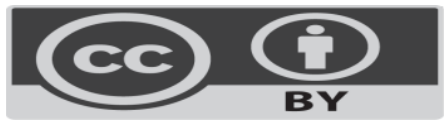


la idea de contribuir con la empleabilidad, término que se ha convertido en un concepto valorado con respecto a la recuperación económica (Formichella y London, 2013). Otra de las manifestaciones de la crisis se da a partir del agotamiento progresivo de los servicios que atienden las necesidades cotidianas de las personas. En consecuencia, surgen diferentes condicionantes para revertir las dificultades al interior y exterior de los sistemas económicos.

Como respuesta a todo lo hasta aquí mencionado, está latente la necesidad de desarrollar competencias en sustentabilidad. Dichas competencias pueden distinguirse en dos tipos: a) aquellas (de carácter técnico) necesarias para desempeñar tareas verdes propias de una economía verde, y $b$ ) las de orden genérico, que tienen que ver con el comportamiento como ciudadanos, consumidores y profesionales. Estas últimas son clave para el desarrollo de proyectos de diseño sustentable, ya que a partir de ellas es posible promover nuevas y mejoradas conductas para atender el problema (Bina, 2013).

En ese sentido, la academia ha buscado afanosamente implementar proyectos de diseño sustentable dentro de la industria a través de diversos métodos y herramientas. Aunque Baumann, Boons y Bragd (2002), y más recientemente Pigosso y Rozenfeld (2011), sugieren que la aplicación y desarrollo de estos instrumentos son en cantidad el mismo número de diseños sustentables implementados en la producción y en la cotidianidad (Bey, Hauschild y McAloone, 2013).

De manera que los proyectos con enfoque en la sustentabilidad han cambiado los sistemas basados en productos por los sistemas con base en los productos y servicios (Manzini, 1999). También Johansson (2002) resalta la necesidad de trabajar con la innovación, las habilidades dentro de la empresa, la relación con el cliente y el compromiso de los directivos, los cuales son factores importantes para estas iniciativas. Incluso, Brones, de Carvalho y de Senzi Zancul (2014) observaron que se requiere trabajar con una visión general de los diversos métodos y técnicas en la industria. Además de manejar un enfoque holístico considerando los diferentes enfoques del proyecto como un sistema único (Fet, Aspen y Ellingsen, 2013) y el aumento de las complejidades en las organizaciones y las dificultades de comunicación en las diferentes etapas de desarrollo de un producto con una 
orientación en el ecodiseño, poniendo en primer lugar el planteamiento, desarrollo y terminación en las propuestas por desarrollar (Verhulst y Boks, 2012).

Por lo anterior, las instituciones de educación superior (IES) tienen un compromiso permanente con la innovación de planes estratégicos para la gestión de proyectos, y su participación no debe restringirse a la formación de recursos técnicos y profesionales, sino involucrar como un requerimiento obligatorio a las organizaciones sociales. Además, se debe trabajar hacia la comprensión total de los diferentes elementos que determinan a un proyecto.

Según la Real Academia Española [RAE], el término proyecto se define, en una de sus acepciones, de la siguiente manera: "Planta y disposición que se forma para hacer un tratado o una ejecución de algo de importancia". Roberts y Wallace (2004) lo describen como 1) un objetivo, producto o resultado único; 2) presenta restricciones (tiempo) y alcance de objetivos; 3) necesita de diversas profesiones, organizaciones y organismos educativos; 4) es único, no se repite; 5) generalmente se desconoce alguno de sus apartados; 6) se trata de una actividad temporal; 7) presenta un inicio y una terminación claramente definidos; 8) todo el proyecto forma parte de un proceso entrelazado, y 9) es relativamente complejo.

Aunado a lo anterior, Roberts y Wallace (2004), este último profesor investigador del Centro de Desarrollo e Implementación de Estrategias (CSDI), presentan algunas definiciones de gestión de proyectos:

a) Proceso de planificación y ejecución de una porción de trabajo desde que se inicia hasta que se termina, encaminado a garantizar el cumplimiento de los objetivos, ajustándose a las limitaciones de tiempo y costo, cumpliendo con las normas de calidad especificadas.

b) Organización, planificación, dirección, coordinación y control de todos los recursos de un proyecto de principio a fin, con el propósito de alcanzar los objetivos del proyecto, dentro de los límites de tiempo y costo, respetando los estándares de calidad exigidos (Roberts y Wallace, 2004, p. 8) 
El CSDI de la Escuela de Negocios de Edimburgo de la Universidad Heriot-Watt trabaja la gestión de proyectos a partir de cuatro áreas que se relacionan entre sí: $a$ ) planificación estratégica; $b$ ) gestión del riesgo estratégico; $c$ ) cómo hacer que funcionen las estrategias, y $d$ ) gestión de proyectos para el cambio (Roberts y Wallace, 2004). Desde otra perspectiva, el estudio de revisión del estado de la ciencia de la innovación y la creatividad en las organizaciones realizado por Anderson, Potočnik y Zhou (2014) hace referencia a los modelos de administración de la innovación dentro de las empresas, considerando que las diferentes prácticas innovadoras de recursos humanos pueden ser el eje transversal en la gestión de proyectos con respecto a sus áreas de aplicación.

Por consiguiente, las IES, a través de sus acciones, tienen la capacidad de crear soluciones y nuevos métodos para atender la transformación que están viviendo las universidades, organizaciones y la población en general, lo que favorece el planteamiento, desarrollo y conclusión eficiente de proyectos de diseño sustentable. Para muchos autores, todos los planteles educativos deberían ser sustentables, considerando que son espacios destinados a la formación de seres humanos. Sin embargo, al interior, se presenta una serie de prácticas que van en perjuicio del medio ambiente y la salud de quienes desarrollan diferentes actividades académicas, administrativas u operativas. Una cantidad importante de afectaciones (construcciones saturadas de materiales, cafeterías que sirven en envases de unicel, desperdicio de papel, abuso del consumo de electricidad, etc.) pueden ser un planteamiento importante para cualquier gestor. Para Frías y Hurtado (2014), un plantel sustentable se encarga primordialmente de cuidar la vida, sus recursos (agua, electricidad), la generación de basura, la equidad y justicia social, ambientes de paz y armonía para favorecer liderazgos que promuevan contenidos ambientales para su currículum educativo. Además, genera estrategias que buscan involucrar directivos, docentes, estudiantes, padres de familia, personal administrativo y de intendencia para planear, operar, evaluar, sistematizar y divulgar sus prácticas de gestión ambiental.

Como parte de los esfuerzos por desarrollar nuevas teorías sustentables en los planteles educativos de educación superior se encuentra el realizado por el Grupo Interdisciplinario de Tecnología Rural (GIRA), el Centro de Investigaciones en Ecosistemas de la Universidad Nacional Autónoma de México (UNAM), el Colegio de la 

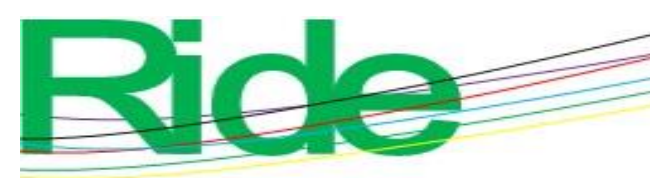

\section{Revista Iberoamericana para la Investigación y el Desarrollo Educativo ISSN $2007-7467$}

Frontera Sur y el Centro de Investigaciones en Ciencias Agropecuarias de la Universidad Autónoma del Estado de México (UAEM). Estos propusieron el proyecto denominado metodología de evaluación de sustentabilidad MESMIS, debido a la petición de la Fundación Rockefeller para desarrollar un método que evaluara la sustentabilidad de los proyectos productivos desarrollados. La expectativa se centró en clarificar y reforzar aspectos teóricos sobre el tema, además de promover recomendaciones técnicas en el manejo de los recursos naturales (Astier, Masera y Galván, 2008). La iniciativa se convirtió en un marco de referencia internacional, y ha servido para formar personal con un enfoque sobre la multidimensionalidad de los procesos de gestión.

Ahora bien, definir un problema a partir de la gestión de proyectos donde intervienen diferentes habilidades como planear, evaluar y decidir, entre otras, resulta un desafío importante, y más aún si se considera que en algunas situaciones se ocupa más tiempo en planear o determinar un problema que en resolverlo. Por ello, se consideró importante plantear las siguientes preguntas: ¿Cuáles son las competencias para la formación y actividad profesional del gestor de proyectos de diseño sustentable? y ¿Cómo interactúan las habilidades del gestor para profesionalizarse en su actividad laboral? También, a través de la investigación, fue necesario determinar objetivos específicos: 1) Identificar y enunciar las capacidades que debe desarrollar un gestor de proyectos de diseño sustentable y 2) Desarrollar alternativas de solución para acceder y beneficiarse de las convocatorias con respecto al desarrollo de proyectos.

\section{Objetivos}

- Estudiar detalladamente las competencias genéricas, específicas y sustentables relacionadas con la gestión de proyectos.

- Hacer un estudio transversal de habilidades para analizar y proponer conceptos relevantes en el planteamiento, desarrollo y conclusión de propuestas.

- Validar los resultados de la aplicación del cuestionario por medio de la teoría de la información para presentar las capacidades requeridas. 

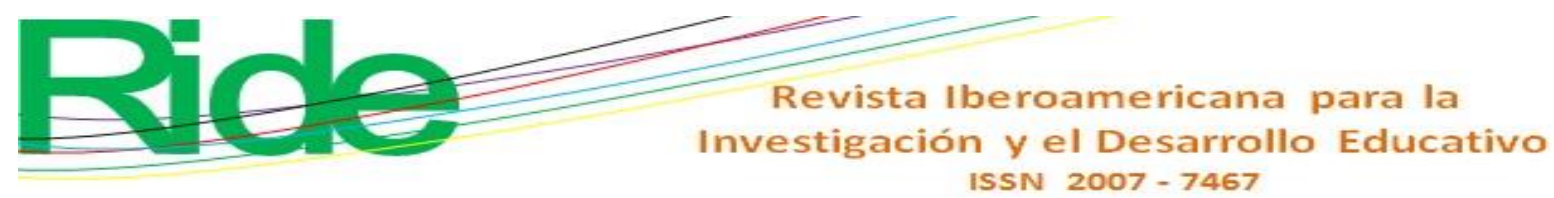

Método

La investigación tiene un enfoque cuantitativo-cualitativo. Se parte de un análisis de datos sobre las competencias genéricas y específicas referentes a la gestión de proyectos para hacer un estudio de transversalidad; definir conceptos y criterios que integren un cuestionario que se aplicará a 20 investigadores de la UAEM, Centro Universitario Valle de Chalco, con el fin de someter los resultados a la teoría de la información (distancia de Hamming) y dar fiabilidad al trabajo. La propuesta se desarrolló en las siguientes fases:

- $\quad$ Fase 1. Para el inicio se propuso un estudio detallado de las características y cualidades que integran las competencias genéricas, específicas y de sustentabilidad para complementar y apoyar la gestión de proyectos.

- $\quad$ Fase 2. En esta parte se desarrolló un análisis de tipo transversal descriptivo, a través de la observación, comparando y evaluando los datos de las diferentes habilidades en las áreas determinadas, con base en la información presentada en los documentos Reflexiones y perspectivas de la educación superior en América Latina: Informe final Proyecto Tuning América Latina: 2004-2007 e Identificación de las competencias específicas más relevantes del diseñador industrial: Un ejercicio para el desarrollo curricular.

- $\quad$ Fase 3. Se aplicó un cuestionario con reactivos preponderantes para la gestión de proyectos de diseño sustentable a 20 investigadores (17 con grado de doctor y 3 de maestro) responsables técnicos de diferentes proyectos de investigación en el Centro Universitario Valle de Chalco. Los resultados obtenidos se validaron con la aplicación de la teoría de la información (distancia de Hamming).

\section{Fase 1. Análisis general de competencias}

Muchos autores han definido el término competencia. Sin embargo, por las características de la investigación, se consideraron solamente las siguientes aportaciones. Según Badilla (2003), las competencias son "capacidades que todo ser humano necesita para resolver, de manera eficaz y autónoma, las situaciones de la vida (p. 35). Beneitone (2007), por su parte, las define de la siguiente forma:

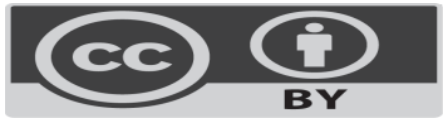



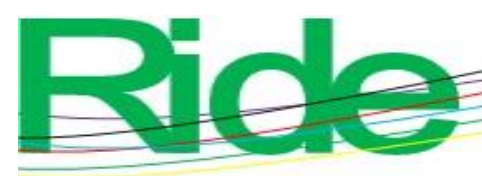

Revista Iberoamericana para la

Investigación y el Desarrollo Educativo ISSN $2007-7467$

Complejas capacidades integradas, en diversos grados, que la educación debe formar en los individuos para que puedan desempeñarse como sujetos responsables en diferentes situaciones y contextos de la vida social y personal, sabiendo ver, hacer, actuar y disfrutar convenientemente, evaluando alternativas, eligiendo las estrategias adecuadas y haciéndose cargo de las decisiones tomadas (p. 35).

Las IES buscan que todos sus estudiantes desarrollen, a partir de la apropiación del conocimiento, la resolución de problemas. De modo que las nuevas estrategias de aprendizaje deberían facilitar la diversificación de saberes. Para conceptualizar las competencias de gestión es importante no olvidar las características sociales, económicas y políticas de América Latina. Las condiciones dan muestra de las capacidades que deben tener los discentes, es decir, deberán tener una preparación cultural e intelectual para hacer frente a los desafíos de convivencia, familiares o laborales. En la Conferencia Mundial sobre Educación Superior (1998) se afirmó lo siguiente: a) es necesaria una mejor capacitación de personal, formación basada en competencias; b) se debe mejorar y conservar la calidad de la enseñanza, la investigación y los servicios, así como la pertinencia de los planes de estudio, y c) es necesario acordar la cooperación e igualdad de acceso a los beneficios referentes a la cooperación internacional. Además, se presentaron las misiones y funciones de la educación superior:

a) Proporcionar las competencias técnicas adecuadas para contribuir al desarrollo cultural, social y económico de las sociedades.

b) Facilitar el acceso a una educación general amplia y especializada para determinadas carreras, a menudo interdisciplinaria, centrada en las competencias y aptitudes, pues ambas preparan a los individuos para vivir en situaciones diversas y poder cambiar de actividad.

c) Propiciar la adquisición de conocimientos prácticos, competencias y aptitudes para la comunicación, el análisis creativo y crítico, la reflexión independiente y el trabajo en equipo en contextos multiculturales.

d) Ratificar y aplicar los instrumentos normativos regionales e internacionales relativos al reconocimiento de los estudios, incluidos los que atañen a la homologación de conocimientos, competencias y aptitudes de los diplomados, a fin de permitir a los

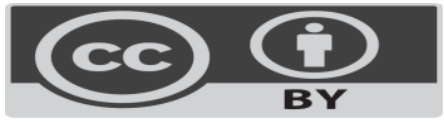



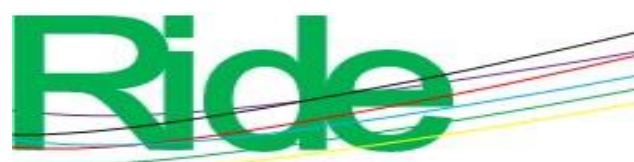

\section{Revista Iberoamericana para la Investigación y el Desarrollo Educativo ISSN $2007-7467$}

estudiantes cambiar de curso con más facilidad y aumentar la movilidad dentro de los sistemas nacionales y entre ellos (Beneitone, 2007, pp. 33-34).

Las competencias genéricas definidas en el informe final del proyecto TuningAmérica Latina 2004-2007 permiten identificar los factores favorables que se presentan en el ejercicio de transversalidad entre las habilidades genéricas y las capacidades que se relacionan con la gestión de proyectos de diseño sustentable. La tabla 1 muestra las competencias con mayor impacto para modificar las actividades de gestión de proyectos. 
Revista Iberoamericana para la Investigación y el Desarrollo Educativo ISSN $2007-7467$

Tabla 1. Listado de competencias genéricas

\begin{tabular}{|l|l|}
\hline Núm. & \multicolumn{1}{|c|}{ Competencia } \\
\hline 1 & Capacidad de abstracción, análisis y síntesis. \\
\hline 2 & Capacidad de aplicar los conocimientos en la práctica. \\
\hline 3 & Capacidad para organizar y planificar el tiempo. \\
\hline 4 & Conocimientos sobre el área de estudio y la profesión. \\
\hline 5 & Responsabilidad social y compromiso ciudadano. \\
\hline 6 & Capacidad de comunicación oral y escrita. \\
\hline 7 & Capacidad de comunicación en un segundo idioma. \\
\hline 8 & $\begin{array}{l}\text { Habilidades en el uso de las tecnologías de la información y de la } \\
\text { comunicación. }\end{array}$ \\
\hline 9 & Capacidad de investigación. \\
\hline 10 & Capacidad de aprender y actualizarse permanentemente. \\
\hline 11 & $\begin{array}{l}\text { Habilidades para buscar, procesar y analizar información procedente de } \\
\text { fuentes diversas. }\end{array}$ \\
\hline 12 & Capacidad crítica y autocrítica. \\
\hline 13 & Capacidad para actuar en nuevas situaciones. \\
\hline 14 & Capacidad creativa. \\
\hline 15 & Capacidad para identificar, plantear y resolver problemas. \\
\hline 16 & Capacidad para tomar decisiones. \\
\hline 17 & Capacidad de trabajo en equipo. \\
\hline 18 & Habilidades interpersonales. \\
\hline 19 & Capacidad de motivar y conducir hacia metas comunes. \\
\hline 20 & Compromiso con la preservación del medio ambiente. \\
\hline 21 & Compromiso con su medio sociocultural. \\
\hline 22 & Valoración y respeto por la diversidad y multiculturalidad. \\
\hline 23 & Habilidad para trabajar en contextos internacionales. \\
\hline 24 & Habilidad para trabajar en forma autónoma. \\
\hline 25 & Capacidad para formular y gestionar proyectos. \\
\hline 26 & Compromiso ético. \\
\hline 27 & Compromiso con la calidad. \\
\hline 28 & Responsabilidad social y compromiso ciudadano. \\
\hline 30 & Compromiso con la preservación del medio ambiente. \\
\hline
\end{tabular}

Fuente: Beneitone (2007, p. 33) 
Las últimas tres capacidades se centran en la responsabilidad social y el cuidado al ambiente, lo cual indica que incluyen un pensamiento sustentable.

También se identificaron las habilidades específicas del área administrativa y su importancia de las actividades de gestión definidas en el mencionado documento. Se trabajó con 700 graduados, 580 empleadores y 681 académicos. La tabla 2 muestra las competencias específicas del área de administración y la tabla 3 contiene los resultados de la importancia relativa de los grupos de interés.

Tabla 2. Listado de competencias específicas para administración de empresas

\begin{tabular}{|l|l|}
\hline Núm. & \multicolumn{1}{c|}{ Competencia } \\
\hline 1 & Desarrollar un planeamiento estratégico, táctico y operativo. \\
\hline 2 & Identificar y administrar los riesgos de negocios de las organizaciones. \\
\hline 3 & Identificar y optimizar los procesos de negocio de las organizaciones. \\
\hline 4 & Administrar un sistema logístico integral. \\
\hline 5 & Desarrollar, implementar y gestionar sistemas de control administrativo. \\
\hline 6 & Identificar las interrelaciones funcionales de la organización. \\
\hline 7 & Evaluar el marco jurídico aplicado a la gestión empresarial. \\
\hline 8 & $\begin{array}{l}\text { Elaborar, evaluar y administrar proyectos empresariales en diferentes tipos } \\
\text { de organizaciones. }\end{array}$ \\
\hline 9 & $\begin{array}{l}\text { Interpretar la información contable y la información financiera para la toma } \\
\text { de decisiones gerenciales. }\end{array}$ \\
\hline 10 & $\begin{array}{l}\text { Usar la información de costos para el planeamiento, el control y la toma de } \\
\text { decisiones. }\end{array}$ \\
\hline 11 & $\begin{array}{l}\text { Tomar decisiones de inversión, financiamiento y gestión de recursos } \\
\text { financieros en la empresa. }\end{array}$ \\
\hline 12 & Ejercer el liderazgo para el logro y consecución de metas en la organización. \\
\hline
\end{tabular}


Tabla 3. Importancia relativa de las competencias específicas para los grupos de empleadores y académicos en el área administrativa

\begin{tabular}{|l|l|l|}
\hline \multicolumn{1}{|c|}{ Competencia específica } & $\begin{array}{c}\text { Media } \\
\text { empleadores }\end{array}$ & $\begin{array}{c}\text { Media } \\
\text { académicos }\end{array}$ \\
\hline $\begin{array}{l}\text { Desarrollar un planeamiento estratégico, } \\
\text { táctico y operativo. }\end{array}$ & 3719 & 3787 \\
\hline $\begin{array}{l}\text { Tomar decisiones de inversión, } \\
\text { financiamiento y gestión de recursos } \\
\text { financieros en la empresa. }\end{array}$ & 3590 & 3643 \\
\hline $\begin{array}{l}\text { Identificar y administrar los riesgos de } \\
\text { negocios de las organizaciones. }\end{array}$ & 3594 & 3633 \\
\hline $\begin{array}{l}\text { Interpretar la información contable y la } \\
\text { información financiera para la toma de } \\
\text { decisiones gerenciales. }\end{array}$ & 3644 & 3631 \\
\hline $\begin{array}{l}\text { Administrar y desarrollar el talento humano } \\
\text { en la organización. }\end{array}$ & 3635 & 3621 \\
\hline
\end{tabular}

Fuente: Beneitone (2007, p.73)

Los datos revelan que los académicos le dan mayor importancia a las competencias de $a$ ) planeación estratégica, $b$ ) toma de decisiones para la inversión y $c$ ) identificar y administrar riesgos de negocios. Los empleadores consideran más relevante lo siguiente: 1) Interpretar información para la toma de decisiones, y 2) Administrar y desarrollar el talento humano.

Parte de la tarea fue analizar las competencias más relevantes para el diseñador industrial. En diferentes momentos, los profesionales del diseño han buscado resolver problemas relacionados con el medio ambiente, la producción y los usuarios. Esto ha generado interés para proponer consensos y definir al diseño, así como sus competencias. En mayo del año 2018 se tuvo la oportunidad de editar el libro intitulado Identificación de las competencias específicas más relevantes del diseñador industrial: Ejercicio para el desarrollo de un plan curricular, gracias a lo cual se logró determinar 10 habilidades específicas considerando el tema de sustentabilidad. La siguiente tabla muestra los resultados de la investigación. 


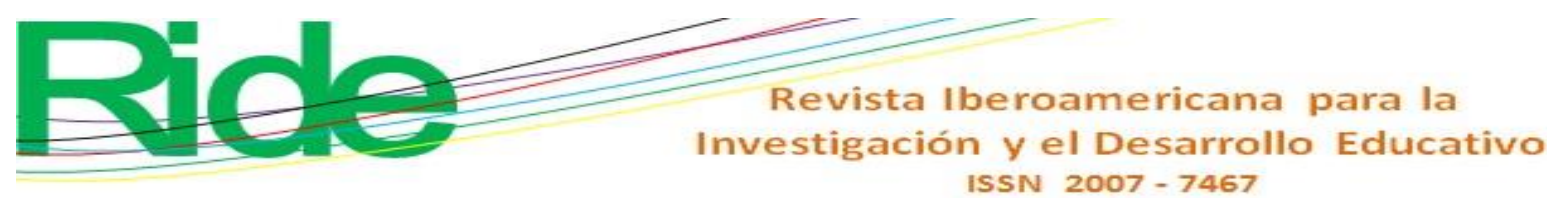

Tabla 4. Competencias específicas de importancia relativa para el diseñador industrial

\begin{tabular}{|c|c|c|}
\hline \multicolumn{3}{|c|}{$\begin{array}{c}\text { Identificación de las competencias específicas más relevantes para el diseñador } \\
\text { industrial }\end{array}$} \\
\hline $\begin{array}{l}\text { 1. Reconocer y analizar los } \\
\text { conceptos de la disciplina, } \\
\text { así como las formas y } \\
\text { estructuras en los conceptos } \\
\text { de diseño para aplicar } \\
\text { tridimensionalmente los } \\
\text { elementos constructivos de } \\
\text { la forma. }\end{array}$ & $\begin{array}{l}\text { 2. Analizar e interpretar los } \\
\text { elementos del estado del } \\
\text { arte de las diferentes áreas, } \\
\text { sustentabilidad, ergonomía, } \\
\text { estética, tecnológicas y de } \\
\text { mercado, para integrar los } \\
\text { elementos con base en } \\
\text { fundamentos de diseño, } \\
\text { creatividad, percepción y } \\
\text { sensibilización para la } \\
\text { elaboración de propuestas } \\
\text { de diseño. }\end{array}$ & $\begin{array}{lr}3 . & \text { Interpretar } \\
\text { sistémicamente } & \text { la } \\
\text { interrelación entre los } \\
\text { factores humanos y otros } \\
\text { sistemas a partir de la } \\
\text { ergonomía y y la } \\
\text { antropometría para su } \\
\text { evaluación y aplicación en } \\
\text { el diseño de artefactos y } \\
\text { objetos industriales. }\end{array}$ \\
\hline $\begin{array}{l}\text { 4. Reconocer y aceptar } \\
\text { proyectos de diseño } \\
\text { industrial que garanticen un } \\
\text { desarrollo sostenible y } \\
\text { sustentable en lo ambiental, } \\
\text { social, cultural y } \\
\text { económico. }\end{array}$ & $\begin{array}{l}\text { 5. Reconocer y seleccionar } \\
\text { la aplicación creativa de los } \\
\text { materiales convencionales y } \\
\text { los de última generación en } \\
\text { problemas específicos de } \\
\text { diseño. }\end{array}$ & $\begin{array}{l}\text { 6. Reconocer el proceso } \\
\text { proyectual como un } \\
\text { método de investigación } \\
\text { para la configuración de } \\
\text { objetos de diseño } \\
\text { industrial. }\end{array}$ \\
\hline $\begin{array}{l}\text { 7. Manejar programas de } \\
\text { diseño asistido por } \\
\text { computadora para la } \\
\text { representación gráfica en } \\
\text { dos y tres dimensiones de } \\
\text { objetos de diseño industrial, } \\
\text { empleando formatos } \\
\text { electrónicos e impresos. }\end{array}$ & $\begin{array}{l}\text { 8. Percibir, concebir y } \\
\text { manejar los materiales de } \\
\text { transición } \\
\text { cartones, (papeles, } \\
\text { laminados plásticos, madera } \\
\text { balsa, yeso plastilina, etc.) } \\
\text { para la representación } \\
\text { tridimensional de objetos a } \\
\text { cualquier escala. }\end{array}$ & $\begin{array}{l}\text { 9. Manejar los medios y } \\
\text { herramientas para realizar } \\
\text { las animaciones y } \\
\text { simulaciones virtuales de } \\
\text { objetos de diseño industrial } \\
\text { con software } \\
\text { especializado. }\end{array}$ \\
\hline $\begin{array}{l}\text { 10. Manejar los medios y } \\
\text { herramientas para } \\
\text { desarrollar modelos } \\
\text { tridimensionales, utilizando } \\
\text { impresoras } \\
\text { estereolitográficas o centros } \\
\text { de maquinados de control } \\
\text { numérico asistido por } \\
\text { computadora o equipos } \\
\text { similares existentes. }\end{array}$ & $\begin{array}{l}\text { 11. Desarrollar proyectos de } \\
\text { diseño industrial que } \\
\text { garanticen un desarrollo } \\
\text { sostenible y sustentable en } \\
\text { lo ambiental, social, cultural } \\
\text { y económico. }\end{array}$ & \\
\hline
\end{tabular}

Fuente: Sánchez (2018, p. 74)

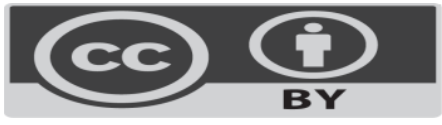


En la tabla presentada se encuentra la competencia que integra el desarrollo de proyectos considerando las teorías de sustentabilidad, las cuales se estructuran por los siguientes ejes de aplicación: 1. Recursos naturales, 2. Sector económico, 3. Equidad social, 4. Sector político y 5. Cultura.

Con respecto a las competencias para la sustentabilidad, se conoce que actualmente existe registro de las actividades que realizan las IES. Por ejemplo, las universidades de España, entre otras, han trabajado por cambios importantes. La Facultad de Ciencias de la Educación en la Universidad la Coruña implantó un sistema de gestión sustentable. Los grupos encargados del proyecto trabajaron de manera monográfica sobre diversos indicadores de administración. En resumen, los objetivos fueron:

1. Eliminar o minimizar los impactos ambientales negativos en la escuela o facultad mediante el control de aquellas actividades que impliquen algún tipo de riesgo para el entorno.

2. Demandar a la comunidad universitaria y empresas que tengan una relación con los procesos académicos, administrativos o de cualquier orden el cumplimiento de la legislación ambiental vigente.

3. Promover la utilización racional de los recursos naturales y la energía.

4. Fomentar prácticas de reutilización, reciclaje y recuperación de materiales, a fin de minimizar la producción de residuos y su incidencia en el medio.

5. Desarrollar programas de formación dirigidos a toda la comunidad universitaria para promover el desarrollo de actitudes positivas hacia el desarrollo sustentable en el desempeño de sus funciones.

6. Hacer del campus un entorno amigable (protección de espacios verdes, mejora de accesos, máxima facilidad para la movilidad de personas discapacitadas, etc.).

7. Desarrollar y mejorar cada dos años objetivos y metas proambientales, velando por su cumplimiento mediante evaluaciones periódicas, a través de los sistemas de evaluación (Marcote y Suárez, 2011, p. 212).

La Comisión sobre Calidad Ambiental y Desarrollo Sostenible (Cadep), creada en 2002 a partir de la Conferencia de Rectores de las Universidades Españolas (CRUE), que integra a todas las IES del Estado español, ordenó fomentar la sustentabilidad para los 
estudios universitarios, promover mejores prácticas en la gestión de los recursos naturales, sensibilizar a todos los actores y participar activamente en las iniciativas sociales. Dicha delegación, conformada por más de una docena de facultades universitarias, estudia la propuesta de sustentabilidad curricular con el fin de facilitar el proceso de enseñanzaaprendizaje con base en las competencias clave. La línea de investigación consta de tres sublíneas:

1. Diagnóstico e incremento de instrumentos a través de la investigación evaluativa sobre la presencia de capacidades para la sustentabilidad en las titulaciones universitarias (Aznar, Ull, Martínez y Piñero, 2017).

2. Una propuesta metodológica innovadora de los procedimientos formativos de los estudiantes universitarios para reforzar la adquisición de las habilidades clave en sustentabilidad (Melendro, Murga, Novo y Bautista, 2008).

3. La formación del profesorado en las competencias necesarias para liderar procesos pedagógicos en el marco de la educación para el desarrollo sustentable tanto de la formación inicial como permanente (Vilches y Pérez, 2012).

Derivado de estas líneas de trabajo, la Cadep sugiere que se integren cuatro competencias generales para la sustentabilidad. La tabla 5 muestra estas competencias.

Tabla 5. Competencias clave para la sustentabilidad

\begin{tabular}{|l|l|}
\hline Núm. & \multicolumn{1}{c|}{ Competencia } \\
\hline 1 & $\begin{array}{l}\text { Competencia en la contextualización crítica del conocimiento estableciendo } \\
\text { interrelaciones con la problemática social, económica y ambiental, local y/o } \\
\text { global. }\end{array}$ \\
\hline 2 & $\begin{array}{l}\text { Competencia en la utilización sustentable de recursos y en la prevención de } \\
\text { impactos negativos sobre el medio natural y social. }\end{array}$ \\
\hline 3 & $\begin{array}{l}\text { Competencia en la participación en procesos comunitarios que promuevan } \\
\text { la sustentabilidad. }\end{array}$ \\
\hline 4 & $\begin{array}{l}\text { Competencia en la aplicación de principios éticos relacionados con los } \\
\text { valores de la sustentabilidad en los comportamientos personales y } \\
\text { profesionales. }\end{array}$ \\
\hline
\end{tabular}

Fuente: Cadep (2012) 


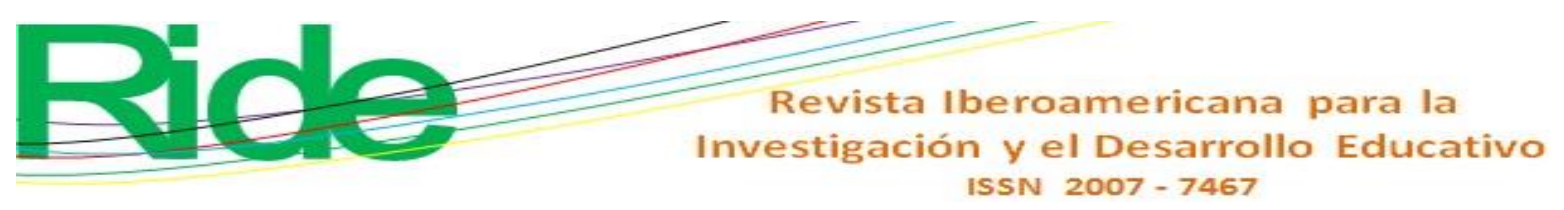

Fase 2. Estudio de transversalidad

Para definir las competencias en la gestión de proyectos, se tomaron las capacidades analizadas, al igual que las que debe tener un director. El Project Management Institute (PMI), en su Guía de fundamentos para la dirección de proyectos [Guía del PMBOK] (2013), declara que esta actividad es una disciplina estratégica crítica, por lo tanto, el líder debe comprender, generar y aplicar conocimiento, herramientas y técnicas para gestionar proyectos de manera eficiente, además de tener habilidades específicas del área y aquellas genéricas transversales para la gestión.

Crawford (2005), por su parte, desarrolló una investigación acerca de las percepciones que tienen los administradores senior sobre las competencias que deben tener los directores de proyecto. Propuso un modelo integrado a partir de la identificación de sus componentes considerando el conocimiento, habilidades, experiencia y características personales, así como las actitudes y comportamiento de los jefes de proyecto. Dicho modelo en conjunto con las competencias de importancia relativa para el área administrativa y las transversales serán la base para conceptualizar las de gestión. La tabla 6 muestra la relación entre los conceptos. 


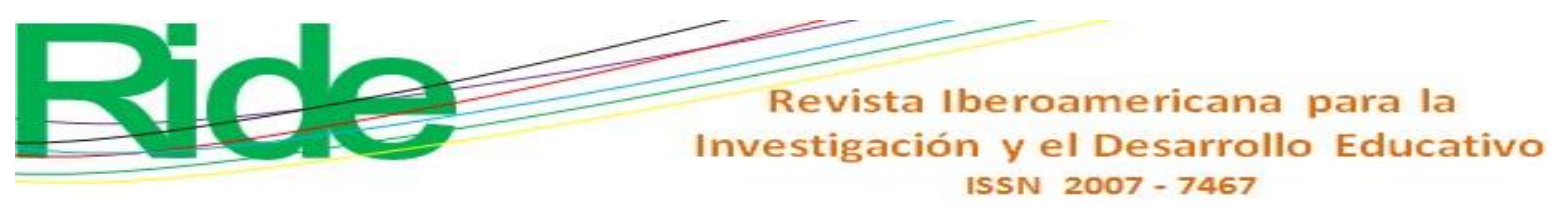

Tabla 6. Análisis transversal de las áreas para la propuesta de competencias importantes en la gestión de proyectos de diseño sustentable.

\begin{tabular}{|c|c|}
\hline $\begin{array}{l}\text { Características de los } \\
\text { proyectos }\end{array}$ & $\begin{array}{l}\text { Tipos de competencias para la gestión de proyectos de } \\
\text { diseño sustentable }\end{array}$ \\
\hline $\begin{array}{l}\text { Un objetivo, producto } \\
\text { resultado único }\end{array}$ & $\begin{array}{l}\text { Capacidad para formular y gestionar proyectos. Co. } \\
\text { Genérica// Desarrollar un planeamiento estratégico, táctico } \\
\text { y operativo. Co. Importancia Relativa-Administración// } \\
\text { Reconocer y aceptar proyectos de diseño que garanticen un } \\
\text { desarrollo sustentable en lo ambiental, social, cultural y } \\
\text { económico. Co. Diseño// Compromiso con la preservación } \\
\text { del medio ambiente. Co. } \\
\text { aplị́̂.Genérica// Competencia en la } \\
\text { de la sustentabilidad en los comportamientos personales y } \\
\text { profesionales. Co. Sustentabilidad// Perspectiva } \\
\text { estratégica. Co. Liderazgo// Competencia en la } \\
\text { contextualización crítica del conocimiento estableciendo } \\
\text { interrelaciones con la problemática social, económica y } \\
\text { ambiental, local y/o global. Co Sustentabilidad// } \\
\text { Perspectiva estratégica. Co. Liderazgo. }\end{array}$ \\
\hline Restricciones (tiempo) & $\begin{array}{l}\text { Capacidad para organizar y planificar el tiempo. } \\
\text { Co.s.spépenérica }\end{array}$ \\
\hline $\begin{array}{l}\text { Requerimientos para el } \\
\text { alcance de objetivos }\end{array}$ & 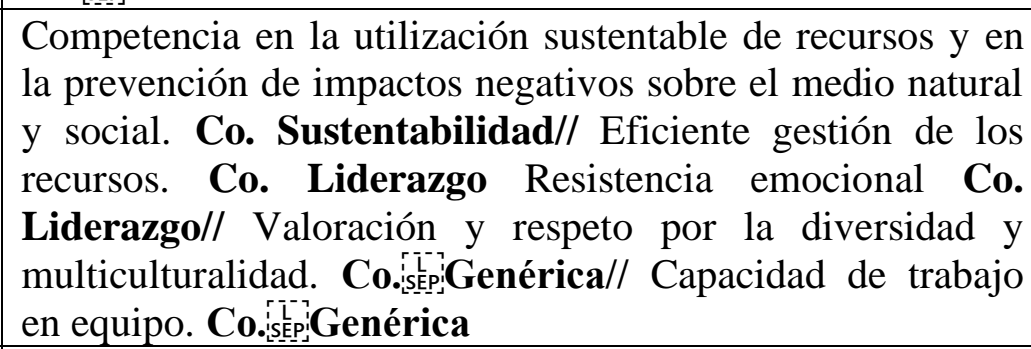 \\
\hline $\begin{array}{l}\text { Requiere de diversas } \\
\text { profesiones, organizaciones } \\
\text { e instituciones }\end{array}$ & $\begin{array}{l}\text { Capacidad de motivar y conducir hacia metas comunes. } \\
\text { iL Co. Genérica// Administrar y desarrollar el talento } \\
\text { humano en la organización. Co. IR-Administración// } \\
\text { Interpretar sistémicamente la interrelación entre los factores } \\
\text { humanos y otros sistemas, a través de las áreas requeridas } \\
\text { para su evaluación y aplicación en el diseño de proyectos } \\
\text { sustentables. Co. Diseño Capacidad de aprender y } \\
\text { actualizarse permanentemente. Co. Genérica }\end{array}$ \\
\hline Es único, no se repite & 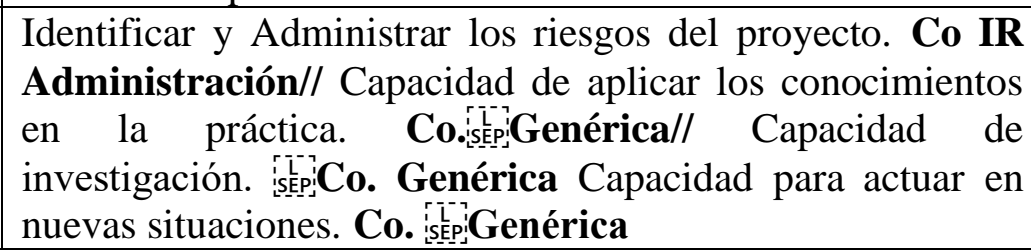 \\
\hline
\end{tabular}




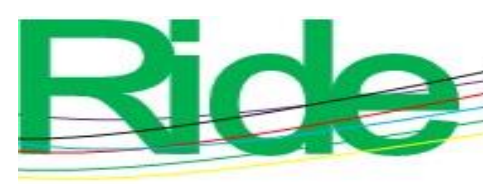

Revista Iberoamericana para la

Investigación y el Desarrollo Educativo

ISSN $2007-7467$

\begin{tabular}{|c|c|}
\hline $\begin{array}{l}\text { Desconocimiento de } \\
\text { algunos de sus } \\
\text { apartados }\end{array}$ & Análisis crítico y juicios. Co. Liderazgo \\
\hline $\begin{array}{l}\text { Se trata de una } \\
\text { actividad temporal }\end{array}$ & $\begin{array}{l}\text { Capacidad para tomar decisiones. Co. Genérica Desarrollar } \\
\text { un planeamiento estratégico, táctico y operativo. Co. IR- } \\
\text { Administración }\end{array}$ \\
\hline $\begin{array}{l}\text { Capacidad para tomar } \\
\text { decisiones. Co. Genérica } \\
\text { Desarrollar } \\
\text { planeamiento estratégico, un } \\
\text { táctico y operativo }\end{array}$ & $\begin{array}{l}\text { Competencia en la participación en procesos comunitarios } \\
\text { que promuevan la sustentabilidad. Co. Administración }\end{array}$ \\
\hline $\begin{array}{l}\text { Todo el proyecto } \\
\text { forma parte de un } \\
\text { proceso entrelazado }\end{array}$ & $\begin{array}{lclr}\text { Competencia en la contextualización crítica } & \text { del } \\
\text { conocimiento estableciendo interrelaciones con } & \text { la } \\
\text { problemática social, económica y ambiental, local y/o } \\
\text { global. Co. Administración }\end{array}$ \\
\hline $\begin{array}{l}\text { Es relativamente } \\
\text { complejo }\end{array}$ & $\begin{array}{l}\text { Capacidad para identificar, plantear y resolver problemas. } \\
\text { Co.ísép.Genérica Capacidad de abstracción, análisis y } \\
\text { síntesis. Co. Genérica }\end{array}$ \\
\hline
\end{tabular}

Fuente: Elaboración propia

\section{Fase 3. Aplicación del instrumento y validación}

Los conceptos resultantes del estudio de transversalidad fueron utilizados para proponer un instrumento con preguntas estratégicas y con base en las características del proyecto y el tipo de competencia de gestión. La finalidad del ejercicio fue facilitar el reconocimiento y consenso de las competencias que los componen. De manera que las IES, por medio de sus directivos, docentes y estudiantes que intervienen en los diversos trabajos, aceleren y mejoren las condiciones con el fin de desarrollar nuevos criterios de administración académica.

Se trabajó con una muestra no probabilística de 20 docentes de tiempo completo e investigadores en seis diferentes licenciaturas (Diseño Industrial, Contaduría, Ingeniería en Computación, Enfermería, Derecho e Informática Administrativa) de la UAEM, Centro Universitario Valle de Chalco; ocho pertenecen al Sistema Nacional de Investigadores (SNI); todos han sido responsables técnicos de proyectos de investigación con enfoque en la sustentabilidad. Cada uno de ellos contestó las preguntas del siguiente cuestionario.

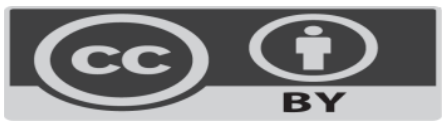


Tabla 7. Descripción (escriba la competencia elegida por nivel de importancia hasta completar 10 de las expuestas en el estudio de transversalidad y desarrolle la información solicitada)

\begin{tabular}{|c|c|c|}
\hline $\begin{array}{l}\text { Nú } \\
\text { m. }\end{array}$ & 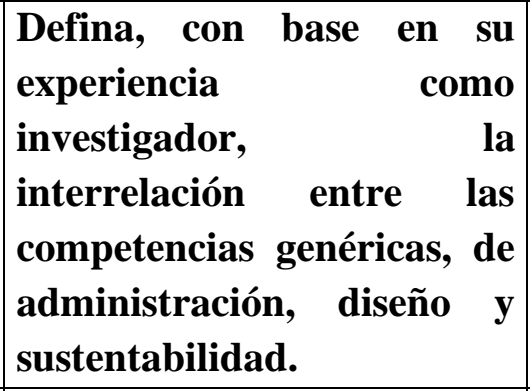 & $\begin{array}{l}\text { ¿Cómo mejoraría su ejercicio } \\
\text { profesional como gestor de proyectos } \\
\text { de diseño sustentable en planteles de } \\
\text { educación superior, a partir de la } \\
\text { implementación de las competencias } \\
\text { que se presentan en el ejercicio de } \\
\text { transversalidad? }\end{array}$ \\
\hline 1 & & \\
\hline 2 & & \\
\hline 3 & & \\
\hline 4 & & \\
\hline 5 & & \\
\hline 6 & & \\
\hline 7 & & \\
\hline 8 & & \\
\hline 9 & & \\
\hline 10 & & \\
\hline
\end{tabular}

Fuente: Elaboración propia

El análisis general del instrumento mostró que las competencias genéricas son relevantes para la gestión de proyectos. Por lo que la transversalidad entre las habilidades generales y las de liderazgo, administración, sustentabilidad y diseño facilitaron la identificación de las capacidades que debe tener, conocer y desarrollar un gestor. 
Figura 1. Valores obtenidos del análisis general de competencias

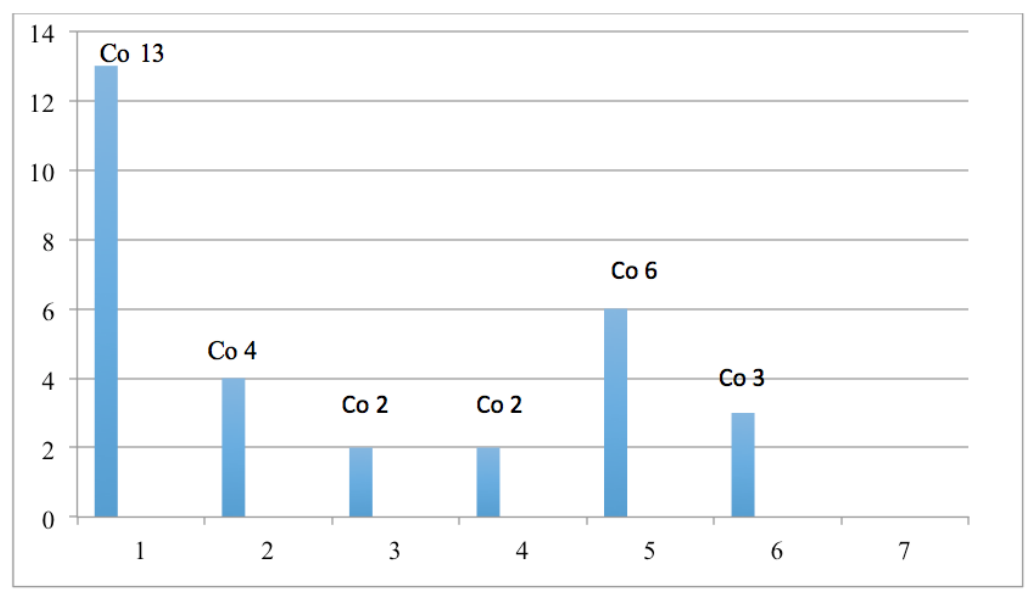

13 Co. Genéricas. 6 Co. Liderazgo. 4 Co. Importancia relativa (administración). 3

Co. Sustentabilidad. 2 Co. Diseño. Y 2 Co. Administración.

Fuente: Elaboración propia

En Teoría de la información se denomina Distancia de Hamming a la efectividad de códigos de bloque (técnicas utilizadas para transformar un conjunto de datos binarios "N" en otro un tanto más largo " $K$ ") y depende de la diferencia entre una palabra de código válida y otra. Cuanto mayor sea esta diferencia, menor es la posibilidad de que un código válido se transforme en otro código válido por una serie de errores. A esta diferencia, precisamente, se le denomina distancia de Hamming y se define como el número de bits que tienen que cambiarse para transformar una palabra de código válida en otra palabra de código válida. Si dos palabras de código difieren en una distancia $\mathrm{x}$, se necesitan $\mathrm{x}$ errores para convertir una en la otra (Hamming, 1950, 90).

La técnica de validación se hizo por medio de dicha teoría: rama de la teoría matemática y de las ciencias de la computación. En el ámbito de la teoría de la información, Claude E. Shannon (ingeniero electrónico y matemático) y Warren Weaver (biólogo e informático) publicaron en 1948 la Teoría matemática de la comunicación (The Mathematical Theory of Communication). Con la aplicación de esta teoría se logró demostrar que todas las fuentes de información pueden medirse y que los canales de comunicación (radio, televisión, teléfono o la gente al hablar, etc.) tienen una unidad de medida similar, y se determinó la velocidad máxima de transferencia o capacidad de canal. 

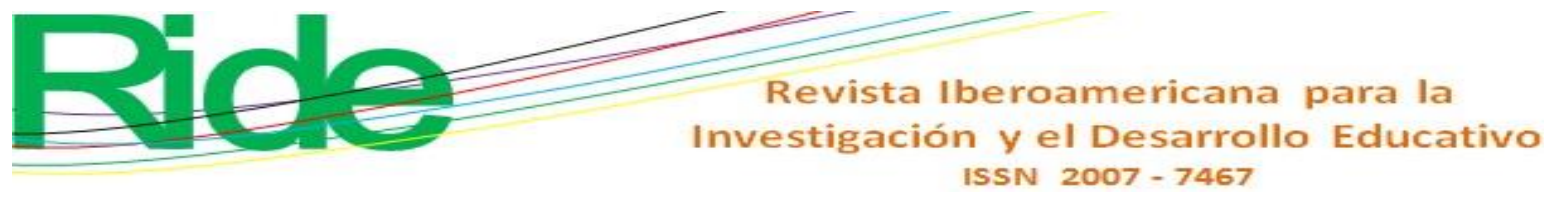

De esta manera, la distancia de Hamming facilita la validación del estudio, ya que permite verificar si la distancia entre el valor estimado real es congruente con el valor estimado ideal. Se analizaron los niveles de frecuencia y la ponderación en una escala de 0 a 10 para las competencias sugeridas. De esta forma, se obtuvo el vector real del nivel de frecuencia. Posteriormente, se aplicó el siguiente algoritmo para definir el vector ideal. La distancia de Hamming se define:

$$
\delta\left[\mu_{A(x)}, \mu_{B(y)}\right]=\frac{1}{n} \sum_{\mathbb{k}=0}^{n}\left|X_{k}-Y_{k}\right|
$$

Donde:

$A(x)$ es el vector de los promedios reales en cada nivel de las competencias sugeridas en el estudio de transversalidad.

$B(y)$ es el vector de los promedios estimados en cada nivel de las competencias redefinidas.

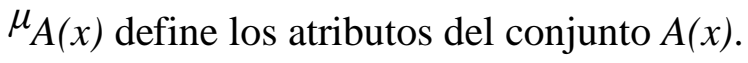

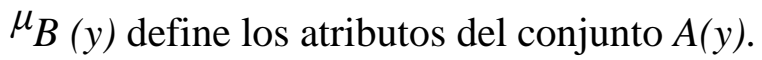

$X_{k}$ es el k-ésimo atributo del conjunto $A(x)$.

$n$ es el total de atributos.

Con esta técnica fue viable detectar la similitud existente entre los vectores reales y los vectores estimados. Por ello, fue posible definir la distancia que existe entre $A(x)$, vector de los promedios reales en cada nivel de las competencias sugeridas en el estudio de transversalidad, y $B(y)$, vector de los promedios estimados en cada nivel de estas competencias. La siguiente gráfica describe el análisis de frecuencia. 

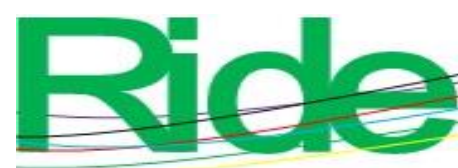

Revista Iberoamericana para la Investigación y el Desarrollo Educativo ISSN $2007-7467$

Figura 2. Análisis de frecuencia de las competencias elegidas por los investigadores

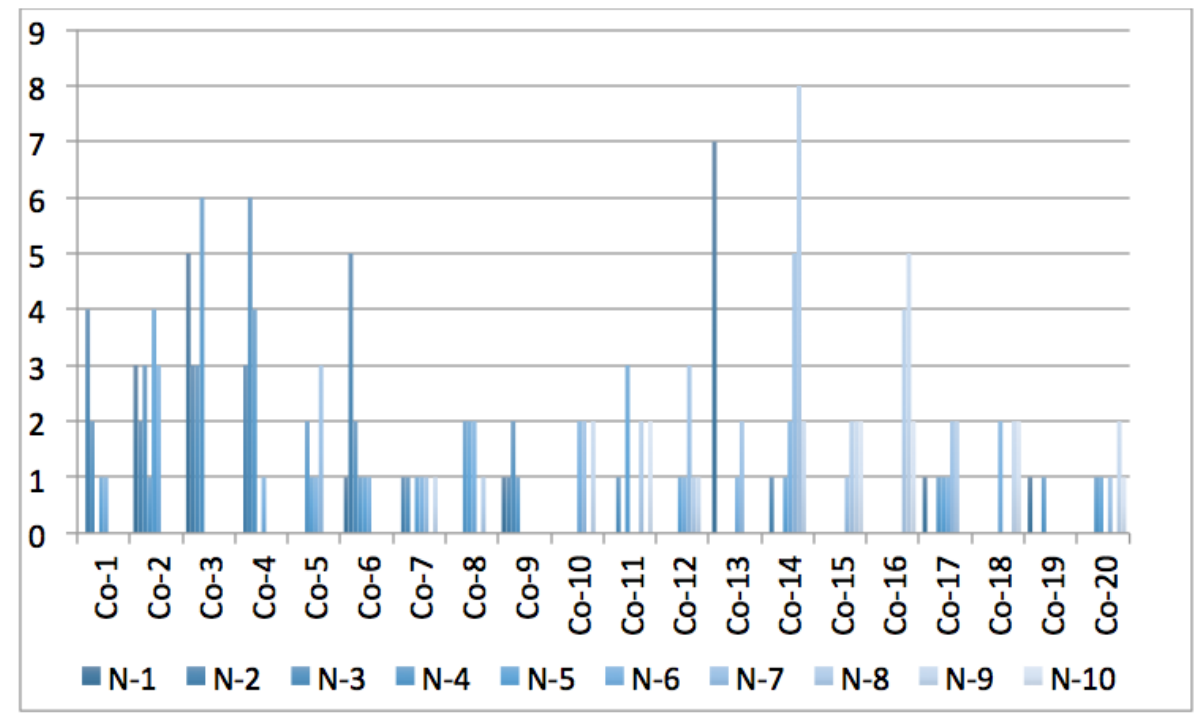

Fuente: Elaboración propia

La distancia promedio establecida entre el estado real derivado del ejercicio de investigación aplicado a los gestores investigadores y el estado ideal encontrado a partir de la técnica utilizada fue de 2.6. La figura 3 lo representa.

Figura 3. Sumatoria vectores reales, vectores ideales y distancia

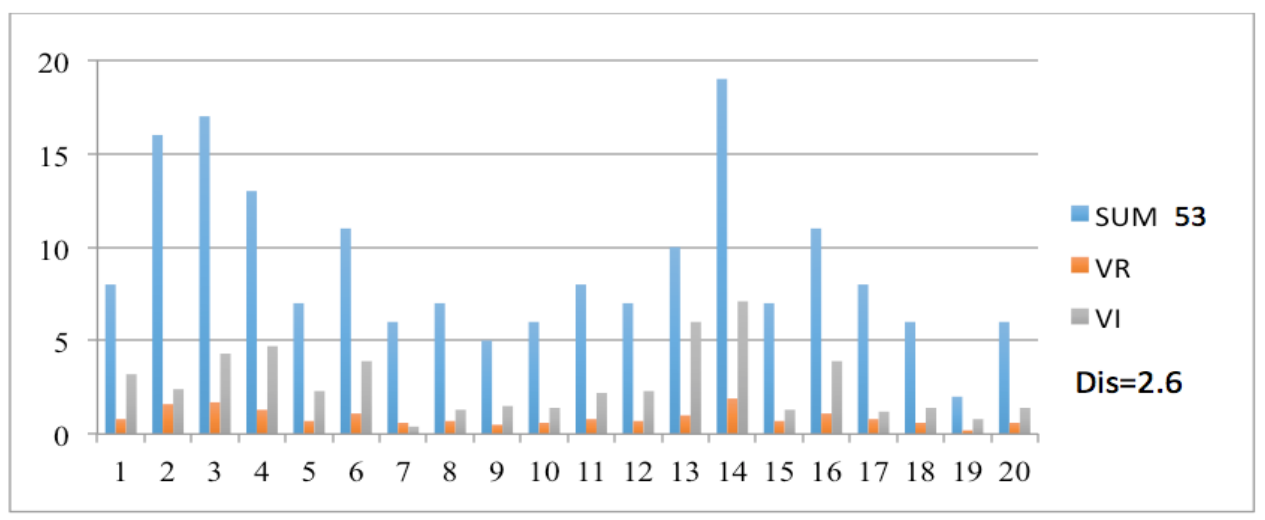

Fuente: Elaboración propia 

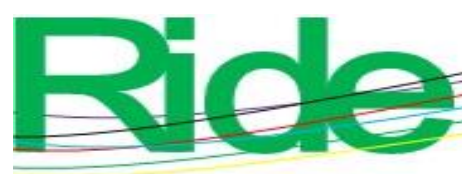

Revista Iberoamericana para la

Investigación y el Desarrollo Educativo

ISSN $2007-7467$

Por lo tanto, se puede decir que las competencias para la gestión de proyectos de diseño sustentable tienen un grado de fiabilidad bastante aceptable. Ya que en una escala de 0 a 10 de este tipo, y cuando se habla de la distancia de Hamming, lo más cercano al valor 0 se considera un resultado altamente satisfactorio, por lo que, para hablar de un proceso de validación de los resultados más robusto, este valor no deberá sobrepasar el 3.

\section{Resultados}

Después de la identificación, análisis y definición de las diferentes capacidades, así como la aplicación del cuestionario y la validación de resultados, se presentan las siguientes competencias para la gestión de proyectos de diseño sustentable:

- Capacidad para planear, formular y gestionar estratégica, táctico y operativamente proyectos de diseño que garanticen un desarrollo sustentable en lo ambiental, social, cultural y económico con una perspectiva estratégica.

- Habilidad para tomar decisiones de inversión, financiamiento y gestión de recursos financieros para el desarrollo de proyectos de diseño sustentable a través de la eficiente gestión de los recursos con visión e imaginación.

- Resistencia emocional para motivar y conducir hacia metas comunes de administración y desarrollo del talento humano en la organización, considerando el valor y respeto por la diversidad.

- Interpretar sistémicamente la interrelación entre los factores humanos y otros sistemas a través de las áreas requeridas para su evaluación y aplicación en el diseño de proyectos sustentables.

- $\quad$ Capacidad de aprender, actualizarse y aplicar conocimientos en la práctica investigativa con respecto a la administración de riesgos del proyecto.

- Habilidad para actuar en nuevas situaciones, a partir de un análisis crítico y juicios para identificar, planear y resolver problemas.

- $\quad$ Competencia en la participación en procesos comunitarios que promuevan la contextualización crítica del conocimiento, estableciendo interrelaciones con la problemática social, económica y ambiental, local y/o global.

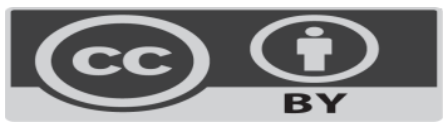



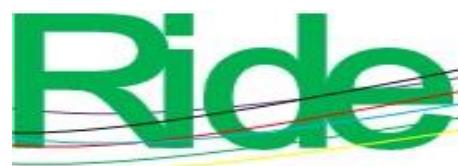

Capacidad de abstracción, análisis y síntesis para organizar y planificar el
Revista Iberoamericana para la Investigación y el Desarrollo Educativo ISSN 2007 - 7467

tiempo.

\section{Discusión}

En la investigación surgieron diferentes criterios que pueden fortalecer el emprendimiento de proyectos, aunque lo complicado para iniciarlos se presente en la dinámica demográfica y los patrones políticos con base en procesos burocráticos dados en un sistema local, estatal o federal. De acuerdo con Manzini (1996), es necesario generar una nueva manera de hacer productos y diseño, debido a que el ambiente artificial del hombre tiende a ser cada vez más desechable, ya que las iniciativas o programas que se desarrollan en un contexto amigable con el medio ambiente solo benefician a unos cuantos.

Además, se logró exponer la necesidad de atender la incompatibilidad entre los modelos de producción y consumo vigentes. A pesar de ello, los factores económicos sobrepasan el uso racional de los recursos naturales, la interacción y entendimiento en las distintas actividades humanas, así como la versatilidad para que los objetos diseñados puedan reconfigurar continuamente su entorno y aprovechar eficientemente los recursos naturales y materias primas.

\section{Conclusiones}

Está claro que la gestión de proyectos parte de una perspectiva técnica y se encamina hacia una social, por ello es necesario reconsiderar nuestro comportamiento en los centros de educación superior, empezando por las actividades cotidianas familiares, las relaciones circunstanciales con las demás personas, los hábitos de consumo, el uso de bienes y servicios hasta las acciones más estructuradas y sus consecuencias derivadas del desconocimiento de algún tema. Por consiguiente, para generar proyectos de diseño sustentable en los planteles educativos es necesario abordar conjuntamente el desarrollo de competencias con base en las teorías y criterios de la sustentabilidad, técnicas propias de la gestión y programas que se enfoquen transversalmente en las conductas de las personas. En 

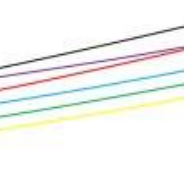

\section{Revista Iberoamericana para la Investigación y el Desarrollo Educativo ISSN $2007-7467$}

ese sentido, se requiere identificar y modificar si es necesario el comportamiento proambiental que presentan los directivos, investigadores, estudiantes y la comunidad universitaria. Actualmente los cuerpos académicos o grupos de investigación de las IES en diseño trabajan hacia los procesos globales de producción, sin tomar en cuenta fuertemente los factores sociales y culturales relevantes para contrarrestar aquellos proyectos que se evalúan como contaminantes.

La gestión de proyectos en las organizaciones ha utilizado elementos académicos como investigativos, considerado diferentes enfoques centrados en la ejecución de tareas, gestión de competencias, desarrollo de funciones y de nuevos criterios de actuación. A pesar de todo este material, actualmente no se puede determinar un método que garantice el total éxito de un proyecto. No obstante, cualquiera que sea la especialidad de un gestor, no impide que trabaje hacia nuevas formas de pensamiento. Las herramientas que utilizan aquellos que pretenden hegemonizar la economía, la producción y los recursos naturales en su beneficio no alcanzan los valores éticos y de contextualización que se requieren para controlar la desmedida devastación del planeta en que vivimos. Por lo tanto, las nuevas generaciones, en conjunto con los profesionales experimentados, deben comprometerse con innovadores modelos para el desarrollo de proyectos y generar conocimiento, así como resultados satisfactorios. Los proyectos de diseño sustentable son herramientas que deberán equilibrar la cultura material, los sectores tecnológicos, económicos, educativos, políticos y culturales en favor de la calidad de vida. 


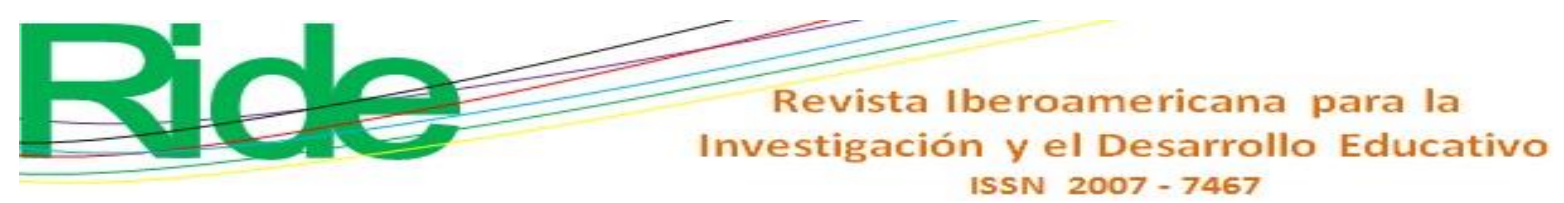

\section{Referencias}

Ali, F., Boks, C. and Bey, N. (2016). Design for Sustainability and Project Management Literature-A Review. Procedia CIRP, 48, 28-33.

Anderson, N., Potočnik, K. and Zhou, J. (2014). Innovation and creativity in organizations: A state-of-the-science review, prospective commentary, and guiding framework. Journal of management, 40(5), 1297-1333.

Astier, M., Masera, O. R. y Galván-Miyoshi, Y. (coords.) (2008). Evaluación de sustentabilidad: un enfoque dinámico y multidimensional. Valencia, España: SEAE, CIGA, ECOSUR, CIEco, UNAM, GIRA, Mundiprensa y Fundación Instituto de Agricultura Ecológica y Sustentable, España.

Aznar-Minguet, P., Ull, M. A., Martínez-Agut, M. P. y Piñero, A. (2017). Evaluar para transformar: evaluación de la docencia universitaria bajo el prisma de la sostenibilidad. Enseñanza de las ciencias: revista de investigación y experiencias didácticas, 35(1), 5-27.

Badilla, L. (2003). Documentos sobre algunos aportes al concepto de competencias desde la perspectiva de América Latina. Tuning América Latina, 2.

Baumann, H., Boons, F. and Bragd, A. (2002). Mapping the green product development field: engineering, policy and business perspectives. Journal of Cleaner Production, 10(5), 409-425.

Beneitone, P. (2007). Reflexiones y perspectivas de la educación superior en América Latina: informe final Proyecto Tuning América Latina: 2004-2007. Bilbao, España: Universidad de Deusto.

Bey, N., Hauschild, M. Z. and McAloone, T. C. (2013). Drivers and barriers for implementation of environmental strategies in manufacturing companies. CIRP Annals, 62(1), 43-46.

Bina, O. (2013). The green economy and sustainable development: an uneasy balance? Environment and Planning C: Government and Policy, 31(6), 1023-1047. 
Brones, F., de Carvalho, M. M. and de Senzi Zancul, E. (2014). Ecodesign in project management: a missing link for the integration of sustainability in product development? Journal of Cleaner Production, 80, 106-118.

Comisión para la Calidad Ambiental, el Desarrollo Sostenible y la Prevención de Riesgos, de la CRUE [Cadep]. (2012). Acta de la reunión del plenario. Salamanca, España: Comisión para la Calidad Ambiental, el Desarrollo Sostenible y la Prevención de Riesgos, de la CRUE. Recuperado de https://www.uah.es/export/sites/uah/es/conoce-la-uah/.galleries/Galeria-dedescarga-de-Conoce-la-UAH/Ecocampus/jornadas-cadep-salamanca.pdf.

Crawford, L. (2005). Senior management perceptions of project management competence. International Journal of Project Management, 23(1), 7-16.

Duarte, C. (coord.) (2006). Cambio Global. Impacto de la actividad humana sobre el sistema Tierra. Madrid, España: Consejo Superior de Investigaciones Científicas.

Fet, A. M., Aspen, D. M. and Ellingsen, H. (2013). Systems engineering as a holistic approach to life cycle designs. Ocean Engineering, 62, 1-9.

Formichella, M. M., y London, S. (2013). Empleabilidad, educación y equidad social. Revista de estudios sociales, (47).

Frías, G. y Hurtado Badiola, M. (2014). Compartiendo saberes para crear planteles educativos sustentables. Canadá y México: Dawson College-Instituto Mexicano para el Desarrollo de Ciudades Verdes.

Hamming, R. W. (1950). Error detecting and error correcting codes. Bell System Technical Journal, 29(2), 147-160.

Johansson, G. (2002). Success factors for integration of ecodesign in product development: a review of state of the art. Environmental Management and Health, 13(1), 98-107.

Manzini, E. (1996) Artefactos. Hacia una nueva ecología del ambiente artificial. Madrid, España: Celeste Ediciones.

Manzini, E. (1999). Strategic design for sustainability: towards a new mix of products and services. In Proceedings First International Symposium on Environmentally Conscious Design and Inverse Manufacturing (pp. 434-437). Tokyo, Japan: IEEE. 
Marcote, P. V. y Suárez, P. Á. (2011). La Agenda 21 y la huella ecológica como instrumentos para lograr una universidad sostenible. Enseñanza de las ciencias: revista de investigación y experiencias didácticas, 29(2), 207-220.

Melendro, M., Murga, M. Á., Novo, M. y Bautista-Cerro, M. J. (2008). Estrategias formativas innovadoras en educación ambiental y para el desarrollo sostenible. RIED. Revista Iberoamericana de Educación a Distancia, 11(2), 15-39.

Økland, A. (2015). Gap analysis for incorporating sustainability in project management. Procedia Computer Science, 64, 103-109.

Organización de las Naciones Unidas [ONU]. (1987). Nuestro Futuro Común. Nairobi, Kenia: Organización de las Naciones Unidas.

Organización para la Cooperación y el Desarrollo Económicos [OCDE]. (2012). Perspectivas ambientales de la OCDE hacia 2050. París, Francia: Organización para la Cooperación y el Desarrollo Económicos. Recuperado de http://www.oecd.org/environment/outlookto2050.

Organización de las Naciones Unidas para la Educación, la Ciencia y la Cultura [Unesco]. (1998). La Educación Superior en el Siglo XXI: Visión y Acción. París, Francia: Organización de las Naciones Unidas para la Educación, la Ciencia y la Cultura.

Pigosso, D. C. and Rozenfeld, H. (2011). Proposal of an Eco Design Maturity Model: supporting companies to improve environmental sustainability. In Glocalized Solutions for Sustainability in Manufacturing (pp. 136-141). Berlin, Germany: Springer.

Project Management Institute [PMI]. (2013). Guía de los fundamentos para la dirección de proyectos (5. ${ }^{\text {a }}$ ed.). Pensilvania, Estados Unidos: Project Management Institute.

Roberts, A. y Wallace, W. (2004). Gestión de proyectos. Edinburgo, Escocia: Business School, Heriot-Watt University.

Sánchez, O. (2018) Identificación de las competencias específicas más relevantes del Diseñador Industrial: ejercicio para el desarrollo curricular (1. a ed.). Pearson.

Turner, R. J., Huemann, M., Anbari, F. T. and Bredillet, C. N. (2010). Perspectives on projects. New York, United States: Routledge. 

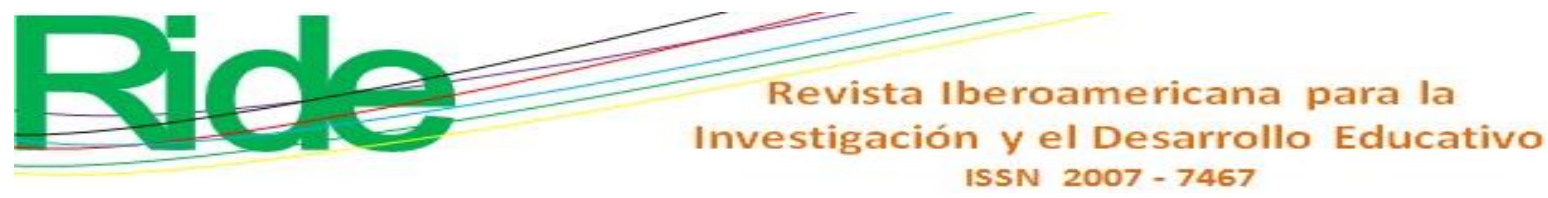

Verhulst, E. and Boks, C. (2012). The role of human factors in the adoption of sustainable design criteria in business: evidence from Belgian and Dutch case studies. International Journal of Innovation and Sustainable Development, 6(2), 146-163.

Vilches, A. y Pérez, D. G. (2012). La educación para la sostenibilidad en la Universidad: el reto de la formación del profesorado. Profesorado. Revista de currículum y formación de profesorado, 16(2), 25-43. 